\title{
Suitability For Parboiling Of Rice Varieties From Benin Through Assessing The Soaking Temperature And Rice Quality
}

\author{
Ayihadji Ferdinand Paul Houssou \\ Damien Tchatcha \\ Apollinaire Guy Mensah
}

Programme Technologies Agricole et Alimentaire (PTAA) de l'Institut

National des Recherches Agricoles du Bénin (INRAB), Porto-Novo, Benin

\author{
Abdoulaye Kabore \\ Koichi Futakuchi \\ Karim Traore \\ Jean Moreira \\ Aliou Diagne
}

Africa Rice Center (AfricaRice), Cotonou, Benin

doi: 10.19044/esj.2016.v12n21p144 URL:http://dx.doi.org/10.19044/esj.2016.v12n21p144

\section{Abstract}

The suitability of 10 different rice varieties cultivated in Benin for parboiling was assessed through physical, chemical and sensorial analysis. Paddy rice samples were soaked at three different water temperatures (60, 70 and $80^{\circ} \mathrm{C}$ ) under laboratory conditions. Using these temperatures, significant differences $(p<0.05)$ were observed in the chalkiness, hardness and grain homogeneity of the parboiled rice after milling. The paddy rice soaked at $80^{\circ} \mathrm{C}$ presented the best results: the majority of the parboiled grains were homogeneous (overall mean $=85.16 \%$ ) and had favorable scores for hardness (overall mean $=8.99 \mathrm{~kg}$ ) and chalkiness (score $=1$ ). In the field, At soaking temperature about $80^{\circ} \mathrm{C}$ the professional parboilers preferred NERICAL56, BERIS21 and IR841 as the most suitable for parboiling from the investigated rice varieties, due to the grain homogeneity ( $>90 \%)$, head rice ratio ( $>86.67 \%$ ) and low rate of broken grains after milling $(<13.33$ $\%)$. These three varieties were the most appreciated by the panelists before and after cooking, whereas BL19 and NERICA2 were the least. Findings from this work are important for guiding rice parboiling stakeholders in Benin and other countries in West Africa. NERICAL56, BERIS21 and IR841 were the suitable rice varieties for parboiling to be advised to the processors. To this end, passport data on the varieties suitable for parboiling will be 
produced and widely disseminated to the stakeholders for rice parboiling

Keywords: Parboiling, Rice quality, sensory test.

\section{Introduction}

Parboiling of paddy rice (Oryza sp.) is a post-harvest hydrothermal process commonly used for quality maintenance (Ibukun, 2008), improving the nutritional status of the product, reducing the breakage rate upon milling, and imparting different cooking and eating characteristics from nonparboiled rice (Ali and Ojha, 1976, Sakurai et al., 2006,Hardi, 2011). Also, the type of the variety of paddy rice, its physical and chemical feature as well as the post - harvest management greatly influences the quality of rice (Juliano and Bechtel 1985; Juliano and Duff, 1989; Rani et al., 2006). Many varieties of rice are produced and processed for human consumption in Africa (Africa Rice Center, 2007). However, according to parboiled rice processors, not all of these varieties are suited for parboiling. The differences in the varieties are due to the intrinsic characteristics of the paddy, such as the size of the grain, color, amylose content, texture and flavors of the rice after cooking, which influence the appreciation of consumers. This situation raises the question of which among West Africa's rice varieties are suitable technologically and economically for parboiling. The answer to this question will provide useful advice to paddy rice processors to improve their activities. Since 2005, the Africa Rice Center (AfricaRice), in collaboration with the National Agricultural Research Institute of Benin, has developed many improved rice varieties with good agronomic performances. The objective of this study was to compare these varieties and assess their suitability for parboiling. This after a rapid assessment of processors' perceptions of the parboiled rice quality.

\section{Materials and Methods}

\section{Selected rice varieties}

Ten rice varieties were evaluated. Six (NERICA 1, NERICA 2, NERICA 4, NERICA-L 14, NERICA-L 20 and NERICA-L 56) were developed by AfricaRice and four (BERIS 21, BL 19, TOX 4008 and IR 841) were previously cultivated in Benin. All ten varieties were grown under same agronomic conditions (planting period, same zone and agricultural practice) and harvested at full maturity (Ahoyo et al., 2013) at the national rice research station in Benin.

\section{Processors' perceptions of the parboiled rice quality}

The processors' perceptions of the quality of parboiled rice were assessed through rapid appraisal individual surveys in Savalou, Dassa and 
Glazoué. In these three rice-producing regions of Benin, most of the paddy produced is parboiled by the processors. On the basis of established ability, thirty (30) processors were interviewed to learn about their experience and ask them about the different varieties of paddy rice they use, the indicators of good-quality parboiled rice, and the varieties preferred for best-quality parboiled rice.

\section{Parboiling process}

An improved rice-parboiling device was used for the experiment. This device consisted of two parts: a cast aluminum pot and a parboiling vat made of galvanized sheet metal (Houssou et al., 2008). The vat was perforated along its lower base and part of its lateral surface (at 0.25 of its total area) to allow sufficient and uniform steam transmission. It was also fitted with a lid and a hinge to reduce steam loss. For the laboratory research, a small-sized device was used (Fig. 1). The inner diameter and depth of the aluminum pot were $22 \mathrm{~cm}$ and $16 \mathrm{~cm}$, respectively, providing it with a capacity of $6.079 \mathrm{~cm}^{3}$, and a small parboiling vat that could contain more than $2 \mathrm{~kg}$ of paddy rice was used. An automatic gas stove (EUROSONIC), generating uniform and constant heat, was used to parboil the paddy rice in the laboratory.

In the field with the paddy rice processors, a larger size of the improved parboiling device was used (Fig. 2). The inner diameter and depth of the aluminum pot were $50 \mathrm{~cm}$ and $41 \mathrm{~cm}$, respectively; giving it a capacity of $80.462 \mathrm{~cm}^{3}$, and a large parboiling vat that could contain more than $45 \mathrm{~kg}$ of paddy rice was used. A traditional home-improved stove using wood for fuel was used to parboil the paddy rice in the field.

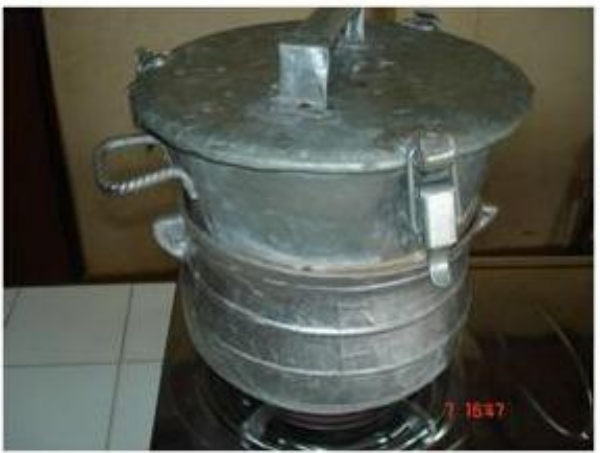

Fig. 1. Small improved rice-parboiling device used in the laboratory

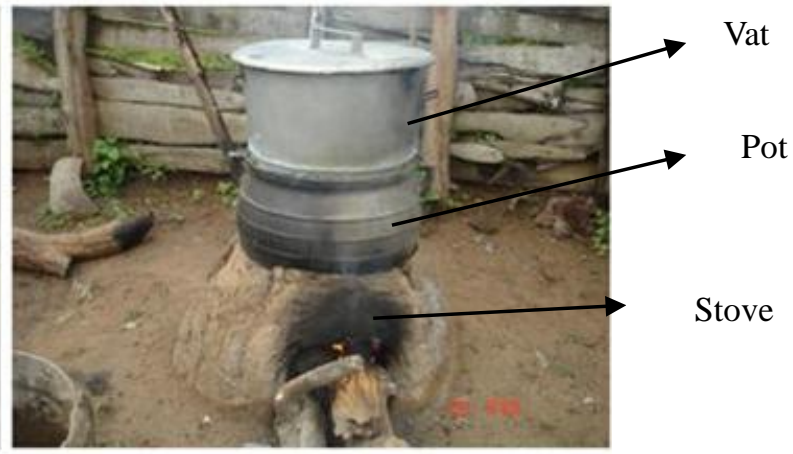

Fig. 2. Medium improved riceparboiling device used in the field

As for the method, the improved rice parboiling method described by Houssou et al. (2008) and Fofana et al. (2011) was used in the Food Processing laboratory at the National Institute of Agricultural Research of 
Benin (INRAB), as well as in the field at Glazoué. Laboratory tests were conducted to determine the appropriate soaking temperature for the paddy rice and the duration for the soaked paddy to cool down and absorb water up to $30-35 \%$. Approximately 32\% moisture content has been reported as appropriate for soaked paddy rice to be ready for parboiling (Islam et al., 2004). Once soaked, the paddy was removed from the soaking water, washed with clean water and drained in a basket. The drained paddy rice was then put in the parboiling vat, which was previously placed on top of a pot containing approximately 1 liter of water (for the small device used in laboratory) or 10 liters of water (for the medium device used in the field).

\section{Experimental design}

In the laboratory, $1 \mathrm{~kg}$ of each of the ten varieties described above was tested at three soaking temperatures $\left(60,70\right.$ and $\left.80^{\circ} \mathrm{C}\right)$ in 1.5 liters of water. Each treatment was repeated at three different occasions. Preliminary experiments had already shown that a soaking temperature lower than $60^{\circ} \mathrm{C}$ did not give good-quality parboiled rice after milling (personal communication). Following the laboratory experiments, the best soaking temperature was used in the field for validation. Fieldwork experiments were performed with female processors parboiling rice at Gomé village in Glazoué (Central Benin). For the experiment in the field, a $20 \mathrm{~kg}$ sample of each of the 10 varieties of paddy rice was parboiled under the same conditions. This experiment was repeated three times for each sample. After parboiling in the laboratory, as well as in the field, the paddy rice was sun dried on a tarpaulin for approximately two hours and thereafter in the shade until the moisture content was approximately 12\%. During the experiment, the temperature was monitored using a probe thermometer (Minitherm HI 875, limits -40 to $+150^{\circ} \mathrm{C}$, Hanna Instruments, Portugal), and the moisture absorbed by the paddy rice was determined using a moisture meter (Wile 55 6F22 9V Digital, Agro Tripette and Renaud, Farmcomp Agroelectronics, Finland). The temperature and moisture absorbed by the paddy rice were each recorded at hour intervals during the cooling of the soaked paddy. After drying, the samples of parboiled paddy rice were milled using a huller (Engelberg Viking No. 1 cover Huller Madras). Because the huller was not equipped with an automatic valve control, the rice obtained after husking was then winnowed.

\section{Measurement of other parameters}

To evaluate the suitability for parboiling the selected paddy rice varieties, the following parameters were measured and compared: soaking and steaming duration, milling duration, milling yield, grain homogeneity ratio, head rice ratio, broken grains ratio, chalkiness, and hardness. The 
energy (fire wood) and water consumption were also recorded.

\section{Soaking and steaming duration}

The duration (Ds) of heating the paddy rice in water to reach the experimental soaking temperature $\left(60,70\right.$ or $\left.80{ }^{\circ} \mathrm{C}\right)$ was measured for each sample. Thereafter, the duration for cooling the paddy rice in its heated water to absorb water to approximately $32 \%$ moisture content was determined. The duration (Dt) of steaming (parboiling) was also determined by measuring the time allocated to the operation. The time was taken from the boiling point to the moment where at least $80 \%$ of the paddy grains on top had their husks split open, indicating the end of the steaming. The moisture content and temperature of the parboiled paddy rice were recorded at this point.

\section{Energy consumption}

The consumed energy was considered to be the quantity of firewood (Q) used during the soaking of the paddy rice plus the quantity of wood used for steam pre-cooking. The same species of wood was used for the treatment of all ten varieties tested.

\section{Milling yield}

The milling yield was evaluated for each tested variety by taking the weight of the rice before husking $\left(m_{1}\right)$ and the weight of the rice after husking and winnowing (\%) Milling yield $=\left(m_{2} / m_{1}\right) \times 100$.

(m2).

\section{Grain homogeneity ratio}

For each sample of milled parboiled rice, a $10 \mathrm{~g}\left(\mathrm{~m}_{0}\right)$ sample was taken and manually sorted under a magnifying glass to separate the homogeneous grains $\left(m_{1}\right)$ from the other grains $\left(m_{2}\right)$ and weighed. This test was repeated three times.

Grain homogeneity ratio $=\left(m_{1} / m_{0}\right) \times 100$.

\section{Head rice ratio and broken grains ratio}

From a $10 \mathrm{~g}$ sample of milled rice, the head rice was manually separated, and the broken grains were weighed. Milled rice grains with a length greater than three-quarters that of complete grains were classed as head rice, and the remaining was considered as broken grains.

Head rice ratio $=$ weight of head rice $(\mathrm{g}) / 10 \mathrm{~g}$.

Broken grains ratio= weight of broken grains $(\mathrm{g}) / 10 \mathrm{~g}$. 


\section{Chalkiness}

Two-hundred whole grains were randomly selected and visually assessed for chalkiness. A score of 1 (less than 10\% chalkiness), 5 (10-20\% chalkiness) or 9 (over $20 \%$ chalkiness) was given to each sample according to the standard evaluation systems of the International Rice Research Institute (IRRI, 1996).

\section{Hardness}

The grain hardness was measured for ten grains from each sample using a Kiya grain hardness tester (Fujihara Seisakusho LDT, Japan). The handle was initially turned to the left to make room to place a grain on the sample table; the handle was then turned to the right until a cracking sound was heard. When the rice cracked, a black pointer returned to the zero point and a red pointer remained to give a reading indicating the hardness of the grain in $\mathrm{kg}$.

\section{Sensory evaluation}

The sensory attribute of the uncooked and cooked parboiled rice was evaluated by 30 panelists who were professional female rice parboilers. A three-point scale ( $1=$ like, 2 = fairly like, $3=$ dislike) was used by the panelists for the evaluation. Sensory attributes such as low broken grain ratio, low chalkiness score, high grain homogeneity (attractiveness), low level of impurities (clean and bright rice) and overall acceptability were considered to evaluate the uncooked parboiled rice. The taste, color, flavor, texture, and overall acceptability were considered for the cooked rice. For each variety, $500 \mathrm{~g}$ of parboiled rice was cooked under the same conditions.

\section{Statistical analysis}

The data obtained were analyzed using analysis of variance processed with SPSS 16.0 at a 95\% confidence level. Means separation was carried out by the least significant difference. Comparative tests were performed with sensory evaluation data using descriptive analysis.

\section{Results and discussion}

\section{Processors' perceptions of the parboiled rice quality}

According to the female processors surveyed, the quality of the parboiled rice was determined by four main criteria: (i) low rate of broken grains, (ii) low chalkiness score, (iii) high grain homogeneity and (iv) low impurity rate. For these four criteria, 93.33\%, 90\%, 83.33\% and 66.66\%, respectively, were obtained from the processors interviewed. According to the processors, the use of an appropriate paddy rice variety and the improved parboiling method, combined with the know-how of the processor, greatly 
contributed to achieving better-quality parboiled rice. Based on this knowledge, 70, 66.66 and 50\% of the processors interviewed indicated that IR 841, BERIS 21 and NERICA-L 20, respectively, were suitable for parboiling in Savalou, Dassa and Glazoué where the survey was conducted.

\section{Parboiling process practiced by experienced parboilers}

Regarding the know-how needed to produce good-quality parboiled rice, the processors indicated that the paddy rice must be soaked in water and heated until the temperature reached a degree at which some bubbles appeared at the surface of the water, or when the processor could not maintain her finger in the water because of the heat. The soaked paddy rice was left in the hot water overnight (approximately 10 hours) to cool down and absorb water. After the paddy rice was removed from the water, it was washed with clean water and drained in a locally made woven basket. The drained paddy rice was then put in the parboiling vat that had been previously placed on top of a pot containing approximately 10 liters of water. The water in this pot did not touch the bottom of the vat; therefore, the rice was steamed until the husks of the majority of the grains on top of the vat were open. The paddy rice was then dried in the sun on tarpaulins and subsequently in the shade for two to three days before being milled. This parboiling practice, as described by the processors, was one of the improved methods reported by Fofana et al. (2011) that led to good-quality parboiled rice. Although this method was described by the processors and reported by some authors as good, there is a need to better assess some processing parameters such as the appropriate soaking temperatures that lead to goodquality parboiled rice. As reported by Sareepuang et al. (2008), the soaking temperature is one of the most important parameters for parboiling rice.

\section{Effect of the soaking temperature on the quality of the parboiled rice}

Parnsakhorn and Noomhorn (2008) found that the optimum temperature for soaking paddy rice was between 72 and $90^{\circ} \mathrm{C}$. Recently, Graham et al. (2015) indicated through surface response methodology (SRM) that the milling yield and head rice yields increased as the initial soaking temperature increased from 30 to $90^{\circ} \mathrm{C}$. Among these temperatures ranges, the most suitable temperature needs to be known to advise rice processors. The results of the present study indicated that soaking paddy rice at $80^{\circ} \mathrm{C}$ provided a better quality of parboiled rice compared with 70 and $60^{\circ} \mathrm{C}$. Table 1 shows the effect of the soaking temperatures on some of the processing parameters and quality attributes of the parboiled rice. Soaking the paddy rice at $80^{\circ} \mathrm{C}$ gave more homogeneous grains (overall mean = $85.16 \%$ ), higher hardness (overall mean $=8.99 \mathrm{~kg}$ ) and low chalkiness score $(=1)$, which are all of the factors that characterize good-quality parboiled rice 
as reported by Kaddus et al. (2002) and Fofana et al. (2011). Compared with $80^{\circ} \mathrm{C}$, a good quality of parboiled rice was not obtained using $60^{\circ} \mathrm{C}$ as the soaking temperature. At $60^{\circ} \mathrm{C}$, the average grain homogeneity was $58.23 \%$, grain hardness was $6.8 \mathrm{~kg}$ and chalkiness score was 5 or 9 (> $20 \%$ chalkiness). Adu-Kwarteng et al. (2003) noted that the presence of chalkiness in rice grain has been described as a "defect" that affects the milling, marketing and storage properties. In this study, soaking the paddy rice at $70^{\circ} \mathrm{C}$ gave an intermediate quality of grain regarding the obtained values (Table 1). In addition, the soaking temperature could influence the processing parameters such as soaking and steaming duration. Soaking the paddy rice at $80^{\circ} \mathrm{C}$ gave better results. At this temperature, the soaking duration of the paddy rice (time left in the hot water to cool in ambient temperature until the moisture content of the paddy grain reached approximately 32\%) was significantly less (the overall mean duration was $3.82 \mathrm{~h}$ ) than the overall mean value of $4.87 \mathrm{~h}$ recorded for $70^{\circ} \mathrm{C}$ and $5.61 \mathrm{~h}$ for $60^{\circ} \mathrm{C}$ for the tested varieties. Kimura et al. (1985) reported that soaking at an elevated temperature not only reduced the duration of soaking but also reduced the risk of contamination of the rice grains by microbial germs due to the thermal effect. However, no significant difference ( $p>0.05)$ was observed for the steaming duration at the tested levels of temperature, regardless of the variety initially soaked.

\section{Suitability of rice varieties to parboiling: processing parameters and physical characteristics of the parboiled rice}

Because soaking the paddy rice at $80^{\circ} \mathrm{C}$ was identified as the best temperature among the three tested, this temperature was used during the fieldwork to assess the suitability of the ten rice varieties for parboiling by the professional female rice parboilers. Tables 1 and 2 shows the parboiling technological parameters and the physical characteristics of the ten tested rice varieties that were parboiled. In the field with the professional women, samples of $20 \mathrm{~kg}$ per variety of paddy rice were processed. After soaking the paddy rice at $80^{\circ} \mathrm{C}$, a significant difference $(\mathrm{p}<0.05)$ was observed between the varieties regarding the time needed to leave the paddy rice in the water until the moisture content of paddy grain reached 32\%. BL 19, NERICAL 14 and NERICA-L 56 had the shortest soaking durations: 6 h 05 min, $6 \mathrm{~h}$ $31 \mathrm{~min}$ and $6 \mathrm{~h} 35 \mathrm{~min}$, respectively, whereas NERICA 2, NERICA 4 and TOX 4008 were the three varieties that needed the longest durations: 8 h 31 min, $7 \mathrm{~h} 29 \mathrm{~min}$ and $7 \mathrm{~h} 12 \mathrm{~min}$, respectively. The rest of the varieties had intermediate soaking durations. No significant difference $(p>0.05)$ was observed regarding the steaming duration; water evaporated during steaming and amount of firewood used for all of the parboiling processes. However, NERICA-L 20, NERICA-L 14 and BERIS 21 gave relatively low steaming 
durations: $24 \mathrm{~min}, 27 \mathrm{~min} 50 \mathrm{~s}$ and $31 \mathrm{~min} 50 \mathrm{~s}$, respectively, whereas TOX 4008, IR 841 and NERICA 2 gave relatively long steaming durations: $39 \mathrm{~min}, 37 \mathrm{~min} 50 \mathrm{~s}$, and $34 \mathrm{~min}$, respectively. Relatively low quantities of evaporated water during steaming were recorded for BL 19, IR 841 and TOX 4008: 7.30 liters, 8.75 liters and 9.12 liters, respectively, whereas relatively high quantities of evaporated water were recorded for NERICA1 and NERICA L14: 11.30 liters and 10.82 liters, respectively. Similarly, for the firewood used, TOX 4008, NERICA 1 and NERICA 2 consumed more firewood: $13.0 \mathrm{~kg}, 11.60 \mathrm{~kg}$ and $11.40 \mathrm{~kg}$, respectively, whereas BL 19, NERICA-L 20 and BERIS 21 consumed less firewood: $10.0 \mathrm{~kg}, 8.80 \mathrm{~kg}$ and $9.60 \mathrm{~kg}$, respectively. Although these relative differences were observed, any correlation between the steaming duration, water evaporated during steaming and firewood consumption was not evident.

Regarding the quality of the milled parboiled rice obtained (Table 2), all of the varieties gave a milling yield greater than $70 \%$. The highest milling yields were obtained with NERICA 4, BERIS 21 and NERICA 1, whereas the lowest milling yields were obtained with NERICA-L14 and TOX 4008. For all of the varieties, the head rice ratio exceeded $80 \%$. For the broken grain ratio, NERICA 1 presented the lowest value, whereas NERICA 2 and IR 841 presented the highest broken grain ratios. In addition, after milling, the rice grains of each sample were very homogenized (> 77\%). BERIS 21 , IR 841 and NERICA-L 56 gave the highest values, whereas NERICA 1 and BL 19 gave the lowest values. TOX 4008, NERICA 4 and IR 841 were the varieties that showed high hardness scores, whereas the lowest values were obtained with NERICA 2 and NERICA-L 56. These results suggested that all ten varieties had good physical qualities in regard to the milling yield, broken grain ratio, homogeneity, head rice ratio and grain hardness. These findings were not surprising because of the improved parboiling method used (Houssou and Amonsou, 2004; Houssou et al., 2008; Manful et al., 2008; Fofana et al., 2011) by the experienced female parboilers. However, the quality of rice is not limited only to its physical characteristics but also to the sensory appreciation of consumers before and after cooking for consumption. 
Table 1. Effect of the soaking temperature on some processing parameters and quality attributes of parboiled rice.

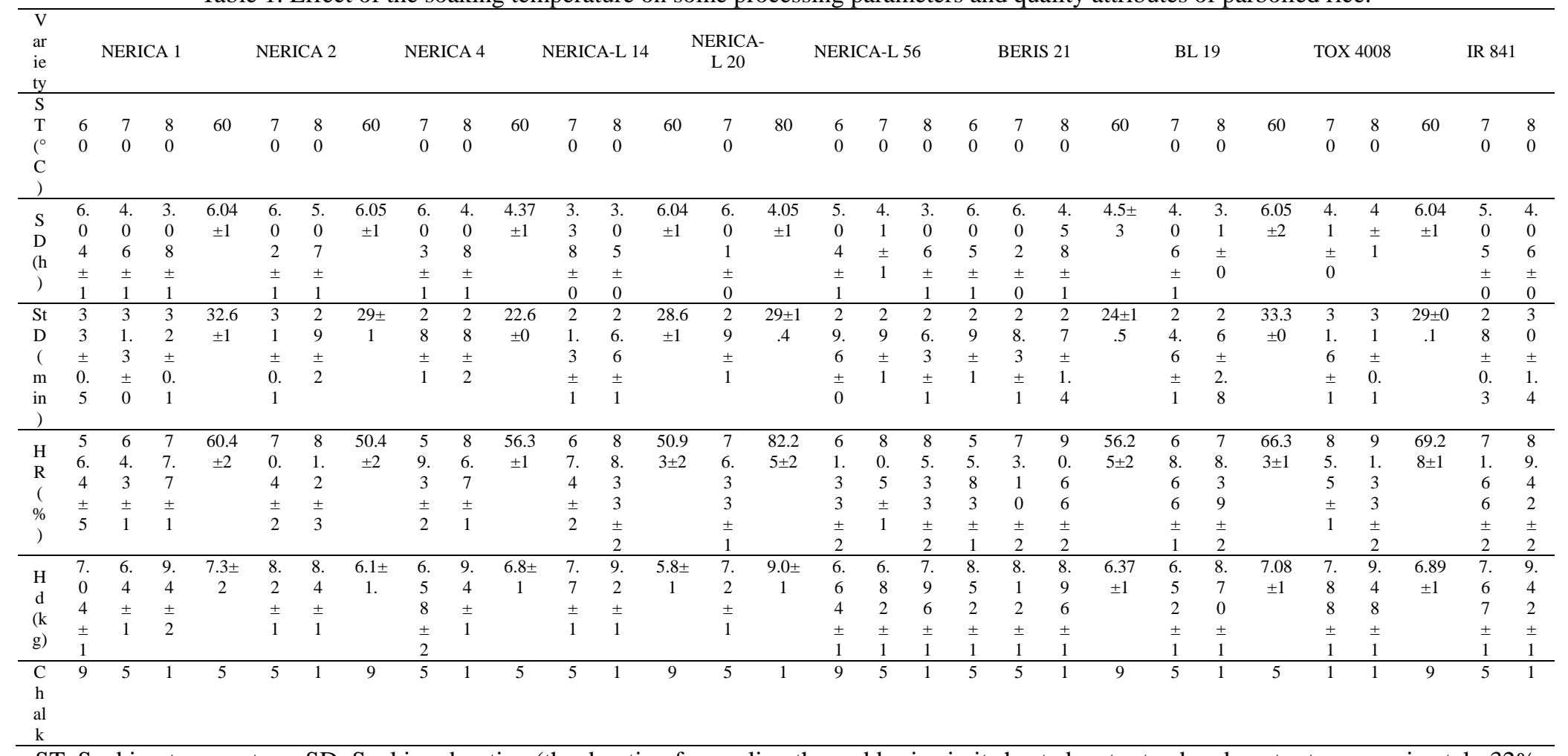

ST: Soaking temperature; SD: Soaking duration (the duration for cooling the paddy rice in its heated water to absorb water to approximately 32\% moisture content); StD: Steaming duration; HR: Homogeneity ratio; Hd: Hardness; Chalk: Chalkiness score 
Table 2. Comparison of the physical characteristics of the ten parboiled rice varieties

\begin{tabular}{ccccccc}
\hline $\begin{array}{c}\text { Rice } \\
\text { variety }\end{array}$ & $\begin{array}{c}\text { Milling } \\
\text { yield } \\
(\%)\end{array}$ & $\begin{array}{c}\text { Head rice } \\
\text { ratio }(\%)\end{array}$ & $\begin{array}{c}\text { Broken } \\
\text { grain ratio } \\
(\%)\end{array}$ & $\begin{array}{c}\text { Grain } \\
\text { homogeneity } \\
(\%)\end{array}$ & $\begin{array}{c}\text { Hardness } \\
(\mathrm{kg})\end{array}$ & $\begin{array}{c}\text { Chalkiness } \\
\text { (score) }\end{array}$ \\
\hline $\begin{array}{c}\text { NERICA } \\
1\end{array}$ & $75.68 \pm 0.01$ & $94.87 \pm 1.04$ & $5.13 \pm 1.04$ & $77.15 \pm 0.78$ & $9.38 \pm 1.53$ & 1 \\
$\begin{array}{c}\text { NERICA } \\
2\end{array}$ & $72.25 \pm 1.41$ & $87.47 \pm 4.63$ & $12.53 \pm 4.63$ & $81.35 \pm 3.04$ & $8.42 \pm 0.80$ & 1 \\
$\begin{array}{c}\text { NERICA } \\
4\end{array}$ & $76.31 \pm 0.01$ & $88.57 \pm 1.17$ & $11.43 \pm 1.17$ & $86.73 \pm 0.56$ & $9.44 \pm 1.12$ & 1 \\
$\begin{array}{c}\text { NERICA } \\
\text { L14 }\end{array}$ & $72.22 \pm 0.72$ & $89.07 \pm 1.65$ & $10.30 \pm 1.65$ & $88.66 \pm 2.06$ & $9.18 \pm 1.13$ & 1 \\
$\begin{array}{c}\text { NERICA } \\
\text { L20 }\end{array}$ & $75.00 \pm 0.14$ & $88.10 \pm 0.62$ & $11.90 \pm 0.62$ & $82.20 \pm 1.56$ & $9.0 \pm 1.15$ & 1 \\
$\begin{array}{c}\text { NERICA } \\
\text { L56 }\end{array}$ & $72.97 \pm 1.42$ & $87.77 \pm 0.9$ & $12.23 \pm 0.90$ & $89.70 \pm 1.64$ & $7.96 \pm 0.82$ & 1 \\
$\begin{array}{c}\text { BERIS } \\
21\end{array}$ & $75.70 \pm 0.73$ & $91.7 \pm 1.22$ & $10.93 \pm 1.22$ & $91.30 \pm 1.49$ & $8.96 \pm 0.82$ & 1 \\
BL19 & $75.67 \pm 1.42$ & $88.37 \pm 0.70$ & $11.63 \pm 0.70$ & $78.36 \pm 1.82$ & $8.70 \pm 0.84$ & 1 \\
TOX4008 & $70.10 \pm 0.01$ & $88.33 \pm 1.00$ & $11.67 \pm 1.00$ & $85.26 \pm 1.56$ & $9.48 \pm 0.72$ & 1 \\
IR841 & $75.00 \pm 1.70$ & $86.67 \pm 0.72$ & $13.33 \pm 0.72$ & $90.39 \pm 1.41$ & $9.42 \pm 1.21$ & 1 \\
\hline
\end{tabular}

\section{Sensory evaluation}

According to the female processors, the best quality attributes of the raw parboiled rice were low broken grain ratio, lower chalkiness score, high rate of grain homogeneity (attractiveness), and low rate of impurities (foreign materials). In this study, the results of the sensory assessment of the raw parboiled rice (Table 3) by the panelists indicated that BERIS 21. NERICA-L 56 and IR 841 were well appreciated by more than $57 \%$ of the panelists, whereas NERICA 1 and BL 19 were the two varieties that were least appreciated by the panelists. Indeed, BERIS 21, NERICA-L 56 and IR 841 were appreciated by the panelists not only due to their cleanliness, bright color and attractiveness but also because of their low rate of broken grains and chalkiness score in comparison with NERICA 1 and BL 19. However, as mentioned by the panelists, the best quality of parboiled rice is also linked to its taste, aroma and texture after cooking. The results of the sensory evaluation of cooked parboiled rice (Table 4) also showed that NERICA-L 56, IR 841 and BERIS 21 were the three most appreciated varieties by the panelists mainly because of their soft texture after cooking. According to the majority of the panelists, BL 19 was not well appreciated due to its stickiness and texture. After cooling, the cooked BL19 looked like 
boiled corn according to the panelists. NERICA 2 occupied the last position because of its taste and color that were not well appreciated by of the panelists. As reported by Manful et al. (2008), the variety is one of the parameters that affect the texture of cooked rice grains. Moreover, Ramesh et al. (2000) reported that the texture of cooked rice grains is expressed in terms of their hardness or firmness (or conversely, their tenderness), stickiness or adhesiveness, and moistness to touch. In the present work, more than $90 \%$ of the panelists preferred cooked NERICA-L 56 because it was still soft even 30 minutes after cooking. IR 841 was chosen by the panelists specifically due to its good aroma, whereas BERIS 21 was preferred mainly because of its taste.

Table 3. Quality evaluation of the ten parboiled rice varieties before cooking.

\begin{tabular}{ccccccc}
\hline \multirow{2}{*}{$\begin{array}{c}\text { Rice } \\
\text { variety }\end{array}$} & $\begin{array}{c}\text { Low } \\
\text { broken } \\
\text { grain ratio }\end{array}$ & $\begin{array}{c}\text { Low } \\
\text { chalkiness } \\
\text { score }\end{array}$ & $\begin{array}{c}\text { High rate of } \\
\text { grain } \\
\text { homogeneity }\end{array}$ & $\begin{array}{c}\text { Low rate of } \\
\text { impurities }\end{array}$ & $\begin{array}{c}\text { Overall } \\
\text { appreciation }\end{array}$ & Rank \\
\hline BERIS 21 & $75.45 \pm 0.39$ & $71.43 \pm 0.40$ & $57.14 \pm 0.10$ & $83.61 \pm 0.28$ & $85.72 \pm 0.20$ & 1 \\
NERICA- & $73.41 \pm 0.42$ & $71.61 \pm 0.28$ & $42.85 \pm 0.12$ & $72.41 \pm 0.42$ & $71.43 \pm 1.11$ & 2 \\
L 56 & & & & & \\
IR 841 & $58.15 \pm 1.32$ & $57.14 \pm 0.61$ & $61.41 \pm 0.42$ & $56.26 \pm 0.52$ & $57.14 \pm 0.10$ & 3 \\
TOX 4008 & $57.14 \pm 0.61$ & $71.41 \pm 0.42$ & $28.57 \pm 0.30$ & $25.14 \pm 0.61$ & $42.86 \pm 0.81$ & 4 \\
NERICA- & $57.14 \pm 0.68$ & $57.14 \pm 0.33$ & $22.85 \pm 0.11$ & $28.57 \pm 0.30$ & $41.50 \pm 0.35$ & 5 \\
L 20 & & & & & & \\
NERICA- & $72.38 \pm 0.44$ & $56.12 \pm 0.16$ & $23.57 \pm 0.05$ & $21.57 \pm 0.33$ & $38.80 \pm 0.14$ & 6 \\
L 14 & & & & \\
NERICA 4 & $57.14 \pm 0.65$ & $28.57 \pm 1.11$ & $18.28 \pm 0.51$ & $20.57 \pm 0.22$ & $28.57 \pm 0.30$ & 7 \\
NERICA 2 & $57.14 \pm 0.47$ & $57.14 \pm 0.10$ & $21.57 \pm 0.45$ & $14.28 \pm 0.51$ & $25.37 \pm 0.45$ & 8 \\
NERICA 1 & $85.71 \pm 0.21$ & $57.14 \pm 0.49$ & $15.28 \pm 0.22$ & $14.28 \pm 0.93$ & $20.80 \pm 0.57$ & 9 \\
BL 19 & $57.14 \pm 0.54$ & $57.14 \pm 0.54$ & $12.28 \pm 0.58$ & $14.28 \pm 1.47$ & $14.28 \pm 0.51$ & 10 \\
\hline
\end{tabular}

Table 4. Quality evaluation of the ten parboiled rice varieties after cooking.

\begin{tabular}{|c|c|c|c|c|c|c|c|c|}
\hline & \multicolumn{7}{|c|}{ Assessment criteria (\% of panelists) } & \multirow[b]{2}{*}{ Rank } \\
\hline $\begin{array}{c}\text { Rice } \\
\text { variety }\end{array}$ & Taste & Color & Flavor & $\begin{array}{l}\text { Texture } \\
\text { before } \\
\text { cooling }\end{array}$ & $\begin{array}{l}\text { Texture } \\
\text { after } \\
\text { cooling }\end{array}$ & Stickiness & $\begin{array}{c}\text { Overall } \\
\text { assessment } \\
(\%)\end{array}$ & \\
\hline $\begin{array}{l}\text { NERICA- } \\
\text { L } 56\end{array}$ & $3.63 \pm 0.97$ & $90.90 \pm 0.07$ & 72 & $63.63 \pm 039$ & $90.90 \pm 0.78$ & 20 & $81.81 \pm 0.57$ & 1 \\
\hline IR 841 & $54.54 \pm 0.96$ & $81.81 \pm 0.35$ & $81.81 \pm 0.84$ & $72.72 \pm 0.40$ & $63.63 \pm 0.30$ & $45.45 \pm 0.60$ & $65.44 \pm 0.46$ & 2 \\
\hline BERIS 21 & $72.72 \pm 0.91$ & $63.63 \pm 0.26$ & $72.72 \pm 1.22$ & $63.63 \pm 0.05$ & $98.10 \pm 1.41$ & $18.18 \pm 0.08$ & $64.48 \pm 1.03$ & 3 \\
\hline NERICA 4 & $72.72 \pm 0.20$ & $54.54 \pm 0.17$ & $54.54 \pm 0.17$ & $45.45 \pm 0.46$ & $63.63 \pm 0.97$ & $63.63 \pm 0.33$ & $63.63 \pm 0.48$ & 4 \\
\hline TOX 4008 & $54.54 \pm 1.03$ & $54.54 \pm 1.09$ & $54.54 \pm 1.09$ & $81.81 \pm 0.06$ & $45.45 \pm 0.67$ & $45.45 \pm 0.53$ & $58.00 \pm 0.65$ & 5 \\
\hline $\begin{array}{l}\text { NERICA- } \\
\text { L } 14\end{array}$ & $54.54 \pm 0.33$ & $36.36 \pm 0.45$ & $45.45 \pm 0.39$ & $63.63 \pm 0.33$ & $81.81 \pm 0.57$ & $54.54 \pm 0.33$ & $57.57 \pm 0.45$ & 6 \\
\hline NERICA 1 & $63.63 \pm 0.26$ & $54.54 \pm 0.33$ & $63.63=$ & $54.54 \pm 0.24$ & $45.45 \pm 1.10$ & $63.63 \pm 0.97$ & $53.78 \pm 0.60$ & 7 \\
\hline $\begin{array}{l}\text { NERICA- } \\
\text { L } 20\end{array}$ & $45.45 \pm 1.10$ & $63.63 \pm 0.47$ & $63.63 \pm 0.34$ & $63.63 \pm 0.80$ & $54.54 \pm 1.03$ & $45.45 \pm 0.25$ & $51.81 \pm 0.49$ & 8 \\
\hline BL 19 & $63.63 \pm 0.47$ & $54.54 \pm 1.03$ & $63.63 \pm 0.97$ & $54.54 \pm 0.04$ & $41.45 \pm 0.39$ & $36.36 \pm 0.45$ & $50.50 \pm 0.54$ & 9 \\
\hline NERICA 2 & $45.45 \pm 0.39$ & $36.36 \pm 0.45$ & $81.81 \pm 0.13$ & $54.54 \pm 0.19$ & $56.36 \pm 0.45$ & $45.45 \pm 0.39$ & $46.46 \pm 0.38$ & 10 \\
\hline
\end{tabular}




\section{Conclusion}

Paddy rice soaked at $80^{\circ} \mathrm{C}$ presented the best parboiled rice quality after milling. Although all of the ten varieties tested appear to be basically suitable for parboiling, the experienced rice parboilers preferred NERICAL 56, BERIS 21 and IR 841 because of their good quality attributes, such as low broken grain ratio at milling, lower chalkiness score, and high rate of grain homogeneity (attractiveness). These varieties were also appreciated by the panelists after cooking. Based on their quality attributes, BL 19, NERICA 2 and NERICA 1 were not greatly appreciated when parboiled, whereas NERICA 4, NERICA-L 14, NERICA-L 20 and TOX 4008 were moderately appreciated by the experienced female parboilers.

\section{Acknowledgements}

The study was partly financed by the Japan Ministry of Foreign Affairs through AfricaRice Center. The authors are grateful to Mr. Jonas Wanvoeke, John Manful and Mr. Zoulkif Midingohi for critical reviewing the manuscript, and all the researchers from the AfricaRice Center. We also sincerely thank Professor Mouhamed M. Soumanou from the University of Abomey Calavi (Bénin) for his guidance.

\section{References:}

Adu-kwarteng, E., Ellis, W.O., Oduro, I. and Manful, J,T. (2003);. Rice grain quality: a comparison of local varieties with new varieties under study in Ghana. Food Control. 14, pp 507 - 514.

Africa Rice Center (2007). Africa Rice Trends: Overview of recent developments in the sub-Saharan Africa rice sector. Africa Rice Center Brief. Cotonou, Benin: Africa Rice Center (WARDA). 10 p.

Ali, N. and Ojha, T.P. (1976): Parboiling. In E.V. Araullo, de Padua D.B. and M. Graham, (Eds.), Rice postharvest technology. Ottawa, Canada: International Development Research Center, pp 163-204

Ahoyo Adjovi N. R., Zoffoun G.A., Adje A.I., Gotoéchan M.H., Adjadohoun A., Mensah G.A. (2013): Technologies éprouvées de production de conservation et de transformation de riz, de l'ananas, de l'anacarde et des produits aquacoles existantes au Bénin. DTI, Dépôt légal n6948 du 04 novembre 2013, $4^{\text {ème }}$ trimestre 2013, bibliothèque nationale $(\mathrm{BN})$ du Bénin. ISBN: 978-99919-1-613-2, pp 1-51.

Fofana, M., Wanvoeke, J., Manful, J., Futakuchi, K., Van Mele, P., Zossou, E., Bléoussi, T.M.R.and ( 2011): Effect of improved parboiling methods on the physical and cooked grain characteristics of rice varieties in Benin. International Food Research Journal. 18, pp 697- 703.

Graham-acquaah, S., Manful J.T., Ndindeng. S. A. and Tchatcha D. A. (2015): Effects of soaking and steaming regimes on the quality of artisanal 
parboiled rice. Journal of Food Processing and Preservation, doi:10.1111/jf pp.12474.

Hardi, M.I., (2011): Effect of parboiling on the quality of processed Degan rice (oryza spp). Kumasi, Ghana: Kwame Nkrumah University of Science and Technology, MSc thesis.

Houssou, P. and Amonsou, E. (2004): Development on improved parboiling equipment for paddy rice in Benin. Uganda Journal of Agricultural Sciences. 9, pp 1019-1026.

Houssou, P.A., Fandohan, P., Mensah, G.A., Klotoé, A. and Mégnaglo, M. (2008): Fiche technique: Guide pratique pour l'utilisation du dispositif amélioré d’étuvage du riz. INRAB, Bénin. Dépôt légal N³773 du 2 Juillet 2008, 3ème trimestre Bibliothèque Nationale (BN) du Bénin ISBN 978$99919-67-92-9$, pp 1-20.

Ibukun, E.O. (2008): Effect of prolonged parboiling duration on proximate composition of rice. Scientific Research and Essays. 3, pp 323 - 325.

IRRI, (1996): Standard evaluation system for rice, 4th edn. Philippines:International Rice Research Institute, pp 1- 102.

Islam, M.R., Shimizu, N. and Kimura, T. (2004): Energy requirement in parboiling and its relationship to some important quality indicators. Journal of Food Engineering. 63, pp 433-439.

Juliano B.O. et Duff B. (1989) : Setting priorities for rice grain quality research. Paper presented at 12th ASEAN Technical Seminar on Grain Postharvest Technology. Surabaya, Indonesia, pp 29-31.

Juliano, B.O. and Bechtel, D.B. (1985): The rice grain and its gross composition. In B.O. Juliano, ed. Rice chemistry and technology, 2nd ed. St Paul, MN, USA, Am. Assoc. Cereal Chem. pp 17-57.

Kaddus, M.A., Anwarul, H., Paul, M. and Brian, C., (2002): Parboiling of rice: Part I: Effect of hot soaking time on quality of milled rice. International Journal of Food Science and Technology. 37, pp 527- 537.

Kimura, T., Bhattacharya, K.R. and Ali, S.Z. (1985): Discoloration characteristics of rice during parboiling (I): Effect of processing conditions on the color intensity of parboiled rice. Journal of the Society of Agricultural Structures, Japan. 24, pp 23 - 30.

Manful, J.T., Grimm, C.C., Gayin, J. and Coker, R.D. (2008): Effect of variable parboiling on crystallinity of rice samples. Cereal Chemistry. 85, pp 92 - 95.

Parnsakhorn, S. and Noomhorn, A. (2008): Changes in physicochemical properties of parboiled brown rice during heat treatment. Agricultural Engineering International. V. X, FP 008- 009 pp 1- 20.

Ramesh, M., Bhatiacharya, K.R. and Mitchell, J. R. (2000): Developments in Understanding the Basis of Cooked-Rice Texture. Critical Reviews in Food Science. and Nutrition. 40, pp 449-460. 
Rani N. S., Pandey M. K., Prasad G. S. V., and Sudharshan I. (2006): Historical significance, grain quality features and precision breeding for improvement of export quality basmati varieties in India. Journal of crop science, 1, pp 29-41.

Sakurai, T., Furuya, K. and Futakuchi, K. (2006): Effects of industrial amassment on the improvement of efficiency and quality. A case study for rice millers in Ghana. In Market and economic development. Tokyo: Keizai Shinpou Sya., pp. 151-179.

Sareepuang, K., Siriamornpun, S., Wiset, L. and Meeso, N. (2008): Effect of soaking temperature on physical, chemical and cooking properties of parboiled fragrant rice. World Journal of Agricultural Sciences. 4, pp 409415. 